\title{
Transnational Engagements: Cultural and Religious Practices Related to Menstruation
}

\author{
Edited by Trisha Maharaj and Inga T. Winkler
}

Many religions and cultures have traditions and practices that influence the activities, experiences, and interactions of menstruators (see Cohen [Chapter 11] in this volume). This dialogue engages participants from various cultural and religious backgrounds to reflect on their personal experiences with menstrual practices. Very often, menstrual practices are presented as restrictive and coercive. However, the participants in this dialogue demonstrate understandings of menstrual practices that reveal a range of engagements with such expectations, including the exercise of agency in various ways.

Can you briefly introduce yourself and your background? Are there practices or traditions related to menstruation in the culture or religion you consider to be your own or with which you are otherwise familiar? Do you follow them?

Rosa Freedman: I live in the United Kingdom as a practicing Jew. In Judaism, the practices and rules about menstruation begin if or when a woman gets married, as those laws relate to what we call taharat hamishpacha (loosely translated as 'family purity'). Those laws involve menstruation, sexual relations, and other aspects of married life (physical, emotional, and spiritual). The simple way of explaining the rules is that a husband and wife do not have intimate relations from the time that menstruation begins until seven days after it ends, when the woman immerses in a ritual bath (mikveh) and is considered spiritually pure. I began following these rules when I got married. As part of the preparations for our wedding, I learned about the spirit and letter of the rules. The day before our wedding, I immersed in the 
mikveh and have done so every month since then, except when pregnant or breastfeeding (see also Mirvis [Chapter 12] in this volume).

Amina Darwish: I am the Muslim Chaplain at Columbia University in New York. Muslim acts of worship are divided into the worship of the heart, tongue and body. The physical acts of worship include salah (the physical prayer), fasting, and vaginal penetration. When women menstruate, we should focus on the worship of the heart and tongue and refrain from the physical acts of worship. My understanding is that our bodies are engaging in another physical form of worship during menstruation. After we finish our menses, we engage in a ritual bath called ghusl before resuming regular salah, fasting, and sexual activity.

Lubabah Helwani: I also live in the United States, and I grew up in a Muslim family. Growing up my family and myself took part in the religious traditions. The day I received my period was a defining moment for myself and my family. I was given a hijab and told that my actions are now my own. We talked about prayers, and a few days later my mother woke me up to pray the early morning prayer. I personally do not take part in any of the religious exclusions when I menstruate. I do not believe that I cannot fast or pray to God while I am on my period. I do believe that my bleeding is a form of prayer and that menstruation is a connection to God in this form.

Lina Mathew: I live in Kerala in India. I am a Syrian Orthodox Christian, while the majority population in Kerala is Hindu. In the Syrian Christian Orthodox and Jacobite churches in Kerala, menstruating women are traditionally not supposed to enter the church or partake of the Holy Communion, and are only permitted to sit outside. While no canon law explicitly bars women from fully participating in church services during their menstrual cycle, such prohibitions do exist within families to varying degrees, and include refraining from touching the Bible, lighting the lamp at home, or participating in religious ceremonies at home. In contrast, there are no religious restrictions for menstruating women in Syrian Catholic and Latin Catholic communities and the many protestant Christian communities in Kerala. As a young girl, based on my mother's protestant beliefs, I used to enter the Orthodox church of my father, even while menstruating. Yet, the two-hour service left me very tired and faint, especially when I got older.

Among many in the Hindu communities of Kerala, some believe that if a woman does not wash her menstrual cloth properly and leaves it lying around, a snake will come across the blood and die by beating its head on a stone. While killing itself, the snake will curse the woman. Many women believe themselves to have been cursed by this mythical snake because of their inability to bear children. Expensive prayers are performed in specific snake temples in Kerala in order to remove such snake curses and beget children. Further, many menstruating Hindu women in Kerala, from across the 
spectrum of castes, do not enter temples until seven days after the onset of menstruation. While women were formerly segregated from the household, nowadays such practices are not so rigid. In other parts of India, I understand that such strict menstrual practices are confined mostly to the upper castes.

Radha Paudel: I was born in a poor, rural family in the central part of Nepal. I have witnessed a variety of practices related to menstruation since I was seven years old, while my mother and three sisters were on their periods. They followed more than 40 types of restrictions related to what menstruating women can eat, touch, or participate in, as well as some related to menstrual blood itself. I was traumatized from seeing all of these restrictions. I also got the opportunity to witness an annual cleansing ritual called Rishipanchami when I was eight years old. Rishipanchami is an annual Hindu festival for purifying the contamination caused by menstruation throughout the year. Menstruating women and girls have to perform the purification ritual so that they can be rid of God's curse of contamination. It was painful seeing my three sisters put in a shed during their first and second period. So, I became determined to deny these restrictions at any cost. I have not followed any of these restrictions since I got my period at the age of 14 .

Kalvi Karunanithy: I grew up in Tamil Nadu, India. When I got my first period I was asked to sit, sleep, and stay outside on the doorstep for three days. On the third day my aunty gave me a shower using yellow water. I felt weird, but was comforted by my parents who slept outside the house to take care of me. However, still I feel that it is a blind belief that people follow, as I didn't feel comfortable asking why we followed those practices at that time. Then my parents did a little puja, inviting all my relatives, and I felt that I got too much attention. This felt strange but I was comforted by many gifts like new dresses, bangles, and gold jewelry. One of my aunties introduced me to cloth as a menstrual absorbent and taught me how to use it during my period. But I was not really educated about menstruation itself. Everything was a bit of a blur for me at that time, and I was too shy to ask any kind of questions, so I kept quiet and blindly followed whatever were the instructions given to me:

I was asked to not to go to temple during my period

I was asked to shower for the first three days of my period and on the third day.

I was asked to take oil bath using ginger oil.

I was asked to not to talk with boys.

I was asked to sleep separately during my period and wash the mat the next day.

I was asked to not to enter the puja (prayer) room at my house.

I was asked not to touch or water the plants during my period.

I was asked to not to feed my own dog. 
As I grew older, I no longer followed any of the orders imposed by my mother, as I didn't like them. For the first couple of months my mother was upset and used to scold me, but after some time, she was all right.

Krystal Ghisyawan: I grew up in a pretty religious Sanatanist Hindu family in Trinidad. It was therefore not uncommon to hear comments about someone being unclean, and having it explained to me that: "The blood is dirty, and puja things have to be clean, so you can't touch anything for the puja." I used to help my mom set up everything for puja. When she "wasn't clean," I did almost all the preparations myself, following her instruction. Sometimes, I too would not be clean, but out of habit, I would still touch things. I might wash a thali (platter) or pass the sugar from the aunties making sweet rice in the kitchen to my mom setting up in the living room. I would exclaim, "Oh I touched it! I'm not clean," but my mom would dismiss it, "It's alright. Didn't you wash your hands?" or "Don't worry about it." Perhaps it was this dismissal that planted the seed of doubt in my mind about how necessary it was to adhere to these practices of purity. This doubt has matured; I am no longer religious.

Jieun Choi: Growing up in South Korea (where I still live), menstrual blood was often considered filthy. In some communities, there was a local custom saying that women shouldn't sit on a broomstick because if it's tainted with their menstrual blood, it'll turn into a monster. Such notions made it clear to women that their menstrual blood needed to be taken care of or else, it'd be of harm to themselves and others. But on the other hand, as menstruation was inevitably linked to women's reproductivity, menstrual blood was considered sacred in some communities. Some say paper dabbed in menstrual blood was used as a charm for a tuberculosis patient in hopes it would help cure the disease. To an extent, such practices still exist in South Korea today. When I was in secondary school, my friends and I would whisper into each other's ears to ask for 'that' and without explicitly mentioning what 'that' is. Then one would discreetly hand over a menstrual pad to another as if she was an illegal drug dealer. Although changing slowly, there is a tremendous taboo surrounding using tampons and menstrual cups in Korea, supposedly due to their 'penetrating' properties. This has to do with the culture that emphasizes women's chastity.

Alfred Muli: I live and work in Kenya, and my impression is that most myths are actually quite similar across Kenya. The menstruating body is viewed as dirty, unclean and one that can contaminate others, hence the taboos that forbid certain activities such as interacting with men, cooking for the family, milking cows, and even going to the garden. One very common belief is that if you go to the garden when menstruating, the crops will dry up. Most of the restrictions draw from either traditional religions or Christianity, banning menstruators from going to places of worship or taking the lead in any religious activities such as standing in the pew or going to the shrines. Most people I know follow these practices. I was recently talking to some university 
students who believe that when your hair is plaited by someone who is menstruating, you get dandruff.

\section{What do you think are the origins of these practices or traditions?}

Rosa Freedman: The Jewish practices are grounded in rules found in religious scriptures. The rules of what a married woman and married man can and cannot do during menstruation and the seven days afterwards are set out in the Gemarrah (Talmud) and other Jewish texts that expand upon the rules that govern our everyday practices. The rules encourage a marital relationship to be based on more than physical or sexual connections, they also provide a method for encouraging fertility (as sexual relations usually begin the day before the most fertile days in the cycle), and they protect a woman at the time of the month when her body is going through significant hormonal and physical changes.

Amina Darwish: In Islam, the practices were narrated by Prophet Mohamed and transmitted to Muslim women through his wife Aisha and his daughter Fatima (peace be upon them). Aisha also narrates instances when Prophet Mohamed (peace be upon him) would show her extra affection while she was menstruating. This was also instructing her to not to try to control matters, but rather let her body do its thing.

Radha Paudel: Nepalese Hindu culture is influenced by Hinduism from India. There are a few Indian Hindu philosophies and epics such as Manusmirti, Chanakyaniti, Garunpuran and Rishipanchami that revealed that menstruation is bad luck, sin from god, dirty, impure and contaminated. In Nepal, almost all people believe that they have to continue the practice for the sake of God and culture. Otherwise some kind of mishap would happen to family members, especially the family head (referring to men members of the family).

Krystal Ghisyawan: South Asians were brought to the Caribbean from the mid-1800s, leaving behind their families, homes, and traditions. Even if they, as individuals, lacked the theoretical or scriptural religious knowledge, South Asians held on to traditional religious practices and passed them on intergenerationally. The traditional purdah practices (meaning partition or separation) kept menstruating women away from the rest of the family, and restricted her chores, like cooking. These restrictions were impractical for women in the Caribbean, who worked for a living and didn't have the support network needed for their chores to be taken on by someone else. While discarded socially, these restrictions still have religious significance; menstrual taboos are only relevant in relation to performing rituals, but are not seen as necessary in everyday life.

What are the religious bases for beliefs that influence menstrual practices? I have never witnessed or heard of a discussion of menstruation at a religious event, yet there are religious myths on the topic. One myth from Vedic time 
stated that women have accepted the sin of the God Indra having killed a Brahmin (highest caste of Hindu). The blood is the manifestation of that sin. This assertion precipitated many questions for me on the nature of sin and karma. Another reason I have been told by a pundit, was that when performing puja, the body is being symbolically given to God. When menstruating, it is as though you are offering the blood to God, too, and blood offerings are considered 'low' forms of worship. Santanists strive for 'high,' 'clean,' or 'pure' worship, the sattvic.

\section{How are these practices generally perceived? And how do you perceive them?}

Rosa Freedman: People who follow these rules tend to see them as liberating in terms of women's bodies, fulfilling in terms of marriage and relationships, and just part and parcel of our everyday practices and the rhythm and cycle of our month. I see it from a feminist perspective-during and after menstruation my body is going through hormonal and physical changes, and the rules enable me to focus solely on my body's needs and not to feel that by doing so I am disregarding my husband's needs or desires. There are women who find these rules restrictive, or others who find it intrusive to be naked in front of the mikveh attendant. But most people I know find it liberating and/ or fulfilling.

Lubabah Helwani: Some women view the breaks in religious practices, such as the daily prayers, as an intifal or celebration. However, many others do not view menstrual practices as positively. Personally, I perceive the religious practices as controlling, fear-based, and a misinterpretation of the religious texts. Many of the religious practices were interpreted, defined, and preached by men. Even if perceived by some as a break, I feel that these breaks have been forced upon us and mean that we cannot take part in our connection with God. However, there are some more current interpretations that differ from those I was taught as a child. These interpretations are new; they are still being explored and discussed.

Amina Darwish: I am very familiar with these new interpretations. Hearing these narrations and gaining new perspective from female scholars was a very empowering experience. I now feel more spiritual during my menses and will focus more on prayer and having deeper conversations with God than I did before. Also, being mindful of my body and my regular menses makes me a better Muslim.

Kalvi Karunanithy: I do not follow all the practices that my elders asked me to follow, I only follow the practices that do not affect me in any way. I respect my mother's feelings and so I don't go to temple during my periods. However, if it were necessary for me to go to temple, I would go for sure. Generally, I find that some practices are restrictive, like asking the girls not 
to go outside or controlling their freedom by forcing them to say at home without providing them with proper reasoning. Other practices are celebratory like the first menarche function, as the girls are given special attention. I would say the practices can have positive aspects as well as negative impacts.

Radha Paudel: In my case, these practices were deeply traumatic. I was shocked when I saw fresh blood on my mother's leg when I was seven years old. My mother awkwardly told me that menstrual blood is sin from God and girls are born with this sin or curse.

There are a few communities that celebrate menarche, but then there are other forms of discrimination associated with menstruation in the same communities. In these instances, these rituals may not truly be celebrations and are instead a way of informally letting it be known that girls are ready for marriage or child bearing. Generally, I find that there is no association with liberty and dignity. They keep saying that now you (as a girl) have to do this and that due to maturity. I do not see any form of liberation or spirituality in this view of menstruation.

Krystal Ghisyawan: When I was religious and interested in participating in rituals, I sometimes used menstruation as an excuse when I wanted a break from all the rituals and prayers we were made to do. It's not like anyone was going to check my panties to determine the heaviness of the flow. There also isn't a chart correlating the heaviness of the flow to the level of impurity, yet I remember being allowed (sometimes forced) to participate in rituals (such as a puja at our home) when the flow was lighter. I also found it paradoxical that I was instructed not to talk about my menstruation, yet I was in a context where this 'private' bodily act was restricting my participation in the public act of worship, making my menstrual status apparent. Ideally, menstruation was supposed to be a secret, not something to advertise or brandish about, because having my period marked my body as a maturing one, preparing for sex and reproduction, other 'secret' and 'private' acts. I use quotations, as there is a false dichotomy between public and private, and none of these processes occur in a singular space or context, neither the pujas nor the menstruation. For instance, daily worship at home (sandhya) is not regulated in the same way as participating in communal rituals, such as pujas or yajnas. Ramleela (a dramatic reenactment of the Hindu epic Ramayana, in Trinidad, performed in improvised open-air theatres in parks and sporting fields) is considered comparable to performing a yajna. When I 'played' Ramleela, I would typically be on the field every night acting various roles, yet almost every year I would get my period during those days. I would dress in regular clothes and stand on the sidelines, finding someone else to fill my role. I was asked rhetorically: "You're not taking part today?" I remember feeling like a spectacle-very self-conscious, but not ashamed. I did not believe there was anything wrong or tainted about my menstruation. Yet hearing the sentence repeated in response to my lack of participation, over and over throughout 
my life, I too would respond in the coded way, "I'm not clean." Under my clothing, no one could see what was taking place, yet the ways in which I dressed and used my body in the space of the temple and the Ramleela, were socially read and understood.

Jieun Choi: I can very much relate to the mixed messages about 'keeping private' and being 'publicly' celebrated or exposed. Generally, I consider the cultural attitudes around menstruation quite restrictive. When I had my first period, my parents congratulated me with a bouquet of flowers for the beginning of my womanhood. But I was extremely ashamed of it because by then, I learned—both culturally and socially — to be ashamed of it.

Alfred Muli: The perceptions of menstrual practices are quite diverse but they are generally seen as restrictions. Menstruators are viewed as unclean and needing to be separated from the rest of society. They are faced with restrictions of what they can do or cannot do. Menstruation is also seen as a sign of physical and emotional maturity and sometimes it is an indicator of readiness for marriage. This is in itself damaging.

\section{What do you see as the benefits of these practices and traditions? What do you see as the risks?}

Krystal Ghisyawan: For women who want to worship, who love puja, or who enjoy practicing Hindu rituals, the rules of ritual purity can be annoying and even alienating. How do I continue to love a tradition that tells me my body is impure and unworthy to be brought before God?

Radha Paudel: Personally, I do not see any benefit at all (though there are some who follow these restrictions who do think there are benefits). I see all of the risks and dangers posed throughout the lifecycle for girls and women. Because of more than 40 types of restrictions related to touch, food, and participation/mobility, women have suffered from nutritional deficiencies, reproductive, and mental health issues, been deprived or absent from educational and economic opportunities, lost their dignity, lost their peace, and lived with chronic humiliation, inferiority complexes and even suicidal thoughts. In west Nepal, some girls and women die due to snake bites, animal bites, accidental fires, suffocation from carbon monoxide, or extreme cold in secluded menstrual sheds. They may encounter rape, sexual abuse, or even murder. More importantly, the development of power dynamics between boys and girls in between the ages of six and eight years old are shaped by menstrual restrictions, which are learned from senior female members in the family and neighborhood. Boys grow up feeling a deep sense of being of super 'powerful' and girls grow up feeling humiliated, inferior, and powerless because they have to go through menstrual restrictions. As was the case for me, they start to see themselves as lowly, accept anything and ask no questions. Meanwhile, boys 
start to exercise their power including abuse towards those they see as less powerful. Thus, gender-based violence including child marriage and sexual assault and rape are directly related to menstrual restrictions within many communities in Nepal. I strongly believe that the menstrual restrictions are one of the underlying causes of conflict and human rights violations.

Lubabah Helwani: I can see the benefits of clearly stating to society that a woman's place in society is a special one, in contrast to what we hear in our everyday life. When young women receive their periods for the first time, they view it as being 'let in on the secret' of being a woman.

Yet, at the same time this 'secret' can be perceived as embarrassing because when they start wearing the hijab, it generally signals to the entire community that they have received their period.

Amina Darwish: For me, the main benefit of our practices is viewing menstruation as Divinely ordained self-care. It also asks women to be mindful of our bodies. This can help women be healthier overall.

Lina Mathew: Men in traditional Hindu families in Kerala are equipped to carry on household chores, and not to complain when women cannot perform their usual household activities. The benefit of these traditions is that women get to rest during these days, especially if they are bleeding profusely and feel faint and tired. The custom of making women sleep separately is perceived to prevent men from having sexual intercourse with their wives, as menstrual blood is considered impure and sexual relations are considered taboo during this period. Yet, at the same time, women may consider separation practices demeaning which may make them hate womanhood.

Rosa Freedman: For me, the biggest benefits are the fact that my husband and I have 12 days per month where we communicate through words rather than touch, which means we talk about things (particularly problems) in detail. We also get excited each month about kissing or touching, let alone sexual relations, because we cannot have those things all of the time. I think this has kept our marriage strong and means we do not take one another for granted.

\section{Who maintains these practices? What, if any, role do men play in these practices?}

Rosa Freedman: It is the responsibility of the woman to check for uterine blood, but of both the woman and man obey the rules. Those include not being naked in front of one another when the woman is a niddah (menstruating or in the period before the mikveh) and not touching each other. My husband and I tend to talk to one another about it, but some couples are more reserved. As to societal pressure-no-one really knows who sticks to the rules, but there is a general expectation that most people do the bare minimum of not having sex during menstruation and the woman immersing in the ritual baths afterwards. 
Lubabah Helwani: Menstruation and its practices and traditions are one of the few aspects that many Middle Eastern women are in control of in their daily lives. Men have no role in the practices and traditions of menstruation. In fact, they try to avoid all conversations that might allude to menstruation.

Radha Paudel: In Nepal, girls learn from friends, mothers, sisters, religious people and activities, both in informal ways and in grounded, deeper ways. The society, especially men as faith healers, teachers, health workers, and political leaders, create fear and anxiety around menstruation by saying that it is dirty and negatively linked with God. They blame menstruating girls and women if something happens to the family or community. No one likes to challenge these restrictions and they simply keep following for the sake of men, God, formality, or power. Men rarely ask women to follow the restrictions publicly, but it is passed down from wives or mothers for the sake of men. When we want to transform these practices, we have to acknowledge that men possess most of the power. Thus, men also have a key role in abolishing restrictions because men are part of the problem. In my experience, the transformative process is easier and faster where boys and men engage with it.

Alfred Muli: Yes, men have a role in maintaining menstrual practices. They tend to 'discipline' their wives or daughters in case they go against any of the traditions. This is mainly in protecting the family name as there would be repercussions in the event that one of the taboos were broken. For instance, it's taboo that anyone sees your menstrual blood. If it happens, you are thought to become barren. In most societies, being barren was seen as a curse, something with which no one would want to be associated. There is pressure to maintain such traditions given their link to other aspects of life that the society deems important such as food scarcity, marriage, or even avoiding upsetting the gods.

Krystal Ghisyawan: The majority of Hindu religious leaders are male, and so have never had to actually confront what it is like to menstruate or to have menstruation interrupt their religious practice. Yet, they play an important role in influencing how women experience their religious practice. Some younger male pundits who I have spoken with thought that practices related to menstruation are not relevant, as women and girls had no control over this part of their anatomy. They emphasized intentionality, that being pure was a matter of cleansing the mind and body.

In your communities, is there social pressure to maintain these practices? Is that changing?

Jieun Choi: The society at large maintains these practices. But amid the active feminist movement in South Korea in the recent years, more and more young women are claiming their rights. More women are informed about 
alternative menstrual products other than menstrual pads, which used to be a fixture among South Korean women. But this is not without dissenters, especially some men who think that using alternative products like tampons or menstrual cups would permanently affect the shape of women's genitalia.

Krystal Ghisyawan: Although within Hindu religious practice in Trinidad it is commonly accepted that menstruation is 'defiling,' 'impure,' and 'unsuited' for worship, observing these rules ultimately falls to women. Menstruation can be a very private act, which gives women and girls the opportunity to choose whether or not they wish to continue the tradition, since they can participate without anyone even knowing they are menstruating. This can give one the power to practice as they see fit, without leaving room for anyone to intervene or interfere. But as religious leaders and elder women reinforce these rules and rituals for younger girls, the practices persist, and girls often learn to regard their own bodies as tarnished and unclean. They may sacrifice their own desires (to participate in ritual) out of respect for this collective belief. What would happen if a girl or woman knowingly participated in ritual while they were having their period? What would happen if someone found out? The potential shaming could also be a deterrent. Ultimately, women police themselves, and in Trinidad and Tobago, most are equipped to resist the practices if they wish to do so, but the societal pressure to conform to traditional practices may be too strong a deterrent to outright rebellion.

Lina Mathew: The concept of menstruation has currently become a very sensitive political issue in Kerala. Recently, a case came up before the Supreme Court of India urging for a ban on the practice of prohibiting women between the ages of 10 and 50 from entering the Sabarimala Ayyappa temple in Kerala. The petitioners argued that this 'menstrual discrimination' leads to social stigma and shame based on gender. It was contended that a woman of menstrual age cannot be treated as 'polluted and untouchable.' In its judgment in Indian Young Lawyers Association and Others v. State of Kerala and Others delivered on September 28, 2018, the Supreme Court of India stated that the practice of banning women between the ages of 10 and 50 from entering the Sabarimala Ayyappa temple is discriminatory and the practice violates the rights of Hindu women (Supreme Court of India 2018). The Court stated that religion cannot be used as a cover to deny rights of worship to women. However, in the months ensuing the Supreme Court judgment, protests were organized by various groups to prevent women of menstrual age from entering the temple. On January 1, 2019 a women's wall, stretching from one end of the state to the other end, was organized by the ruling party of the Kerala Government pledging solidarity to women's rights and standing up against the perception of menstrual impurity. On January 2 , 2019 two Hindu women entered the temple and offered prayers. Riots broke out the next day. However, these women have received support for braving the odds and standing up for women's rights. This case demonstrates that 
menstruation is private and public at the same time. It also demonstrates that it has deeply religious meaning that has a political dimension deemed important enough to spark large-scale protests. Our understanding of menstruation and the practices associated with it go to the core of our understanding of societal norms about gender roles. Active debates regarding the question of purity or impurity of menstruation can alone further dialogue on women's entry into places of worship and change of societal attitudes regarding practices of menstruation.

\section{REFERENCE}

Supreme Court of India. 2018. "Indian Young Lawyers Association v. The State of Kerala on 28 September, 2018." https://indiankanoon.org/doc/163639357/.

Open Access This chapter is licensed under the terms of the Creative Commons Attribution 4.0 International License (http://creativecommons.org/licenses/ by $/ 4.0 /$ ), which permits use, sharing, adaptation, distribution and reproduction in any medium or format, as long as you give appropriate credit to the original author(s) and the source, provide a link to the Creative Commons license and indicate if changes were made.

The images or other third party material in this chapter are included in the chapter's Creative Commons license, unless indicated otherwise in a credit line to the material. If material is not included in the chapter's Creative Commons license and your intended use is not permitted by statutory regulation or exceeds the permitted use, you will need to obtain permission directly from the copyright holder.

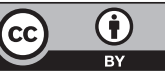

